\title{
Corrigendum: LSD1 is essential for oocyte meiotic progression by regulating CDC25B expression in mice
}

Jeesun Kim, Anup Kumar Singh, Yoko Takata, Kevin Lin, Jianjun Shen, Yue Lu, Marc A. Kerenyi, Stuart H. Orkin \& Taiping Chen

Nature Communications 6:10116 doi: 10.1038/ncomms10116 (2015); Published 02 Dec 2015; Updated 20 Apr 2016 In Fig. $6 \mathrm{f}$ of this article, the histogram label 'Lsd1' should read 'IAP'. The correct version of Fig. 6 appears below.

a
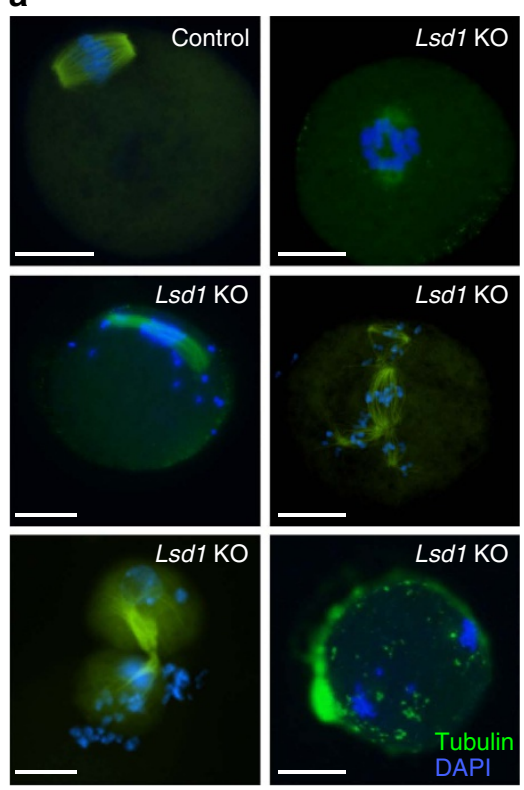

d

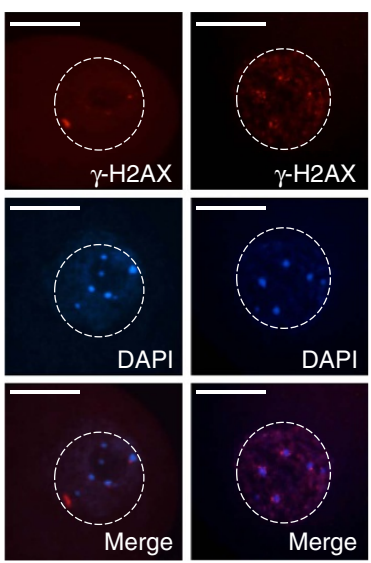

b

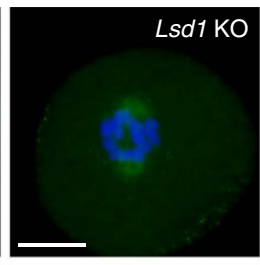

Lsd1 KO

e

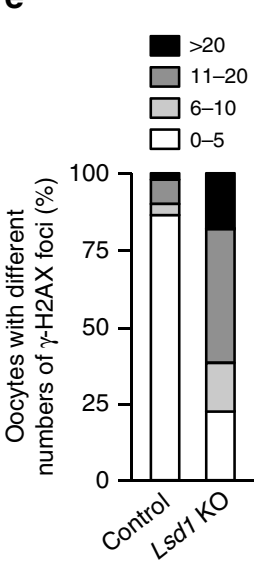

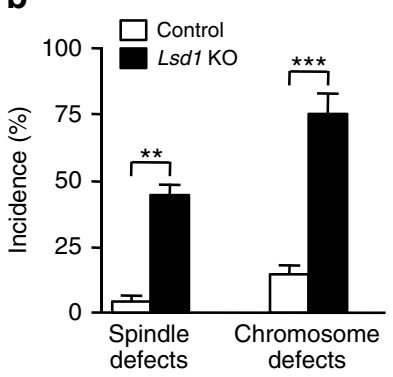

C

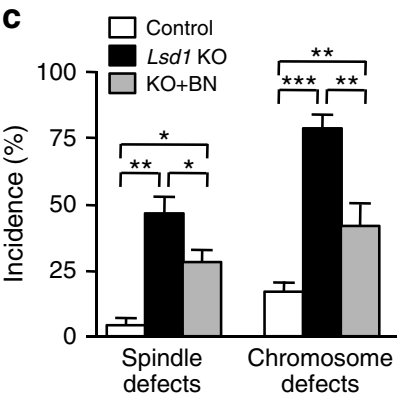

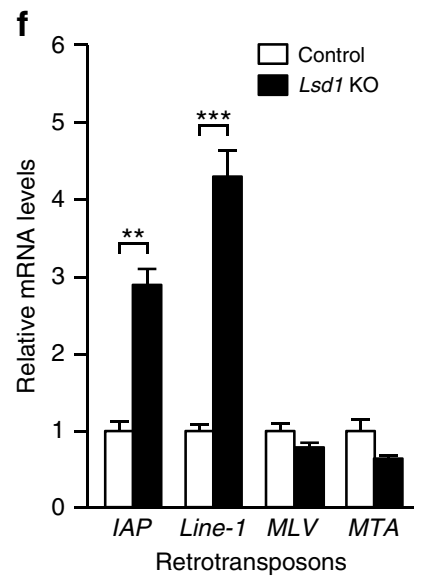


(c) (i) This work is licensed under a Creative Commons Attribution 4.0 International License. The images or other third party material in this article are included in the article's Creative Commons license, unless indicated otherwise in the credit line; if the material is not included under the Creative Commons license, users will need to obtain permission from the license holder to reproduce the material. To view a copy of this license, visit http://creativecommons.org/licenses/by/4.0/ 